\title{
Delivery of Light to Buildings
}

\begin{abstract}
Current method of design and evaluation of interior lighting in buildings is pulverized to the solution of individual spaces. Separately is evaluated energy consumption for lighting in the building. In this situation is very difficult to optimize the lighting systems. The relationship between the needs for lighting and overall energy consumption for lighting is not obvious. Clearer connection can be found in the simplified view of the whole issue. The required lighting levels and thus energy consumption in buildings are affected by three basic aspects. The first aspect is the usage of the building, i.e. what types of visual tasks in a building are exercised. The basic parameter for quantitative evaluation of visual requirements in today's practice is the illuminance $E(I x)$. The second aspect is the size of the building, thus the dimensions of spaces in which the visual tasks are performed. In this case the basic parameter is the illuminated area $A\left(m^{2}\right)$. The last aspect is the time during which the visual tasks are performed, expressed by operating time $T(h)$. In this view the issue of the interior lighting in buildings can be converted to the delivery of luminous flux $\Phi$ (Im) or quantity of light $Q_{\mathrm{V}}$ (Im.h / year). Such expression is conceptually close to requirements for the supply of other media to the buildings, such as heat, air, water etc. The above considerations set the desired amount of luminous flux, respectively quantity of light. The next step is to set lighting quality parameters such as a minimum proportion of daylight, uniformity, limitation of the glare, the colour properties of light. In the last step, the optimal technical solution is found by selecting the type of lighting systems, light sources and luminaires, which meets both quantitative and qualitative requirements of lighting. Such approaches allow the creation of ideas about lighting needs in the initial stages of project and convert them to specific technical solutions.
\end{abstract}

Keywords: Daylighting, artificial lighting, energy consumption, luminous flux, quantity of light.

\section{Introduction}

The paper analyzes the current requirements for lighting in buildings, which are listed in the standards and legislative documents, and suggests a possible way to determine the necessary amount of light for a given building and optimize the lighting system in the initial phase of the building design.

The lighting design in interior spaces is currently determined by two basic aspects, hygienic and energetic. The hygienic aspect takes into account the effect of light on the human health. It relates to the quality of the light environment and it checked through photometric parameters, which connected with the type of visual task and space usage. Photometric parameters are included in the national and international standards and recommendations. The level of quantitative and qualitative lighting requirements is partially based on the current stage of knowledge about the visual perception on the one hand and on the technical and economic possibilities on the other. For this reason, these requirements change over time with regard to the research, the technological developments and economical possibilities of the society.

Hygienic aspect has two levels. The first level means the general lighting requirements with concrete values of photometric parameters for individual visual tasks and activities. The second level means the contribution of daylight to the spaces with concrete usage. General requirements for indoor lighting [1] contain parameters that describe the three basic qualities of the light environment: the amount of light, spectral properties and directional characteristics. The basic variables by which these qualities are described in standards include illuminance, uniformity of light, glare index, color rendering index and semi-cylindrical illumination. From the perspective of the primary considerations about the interior lighting, the areal density of the luminous flux falling on the illuminated surfaces, expressed by illuminance $E_{\mathrm{m}}(\mathrm{Ix})$, is the most important. General lighting requirements for individual visual task are determined without regard to the source of light. To ensure these requirements the daylight and artificial light sources are used.

Hundreds of thousands of year's people evolved under natural lighting conditions to which the human organism adapt. Daylight affects biological processes in the human body and synchronizes our internal biological clock. Daylight color characteristics are taken like a standard for assessment of color rendering. Daylight dynamic changes in color, direction and amount of daylight affect human feelings and emotions. For these reasons, the daylight for humans is essential. In interiors where the people spend a significant part of day (apartment, office, workshop etc.) a contribution of the daylight is required. The level of illumination provided by natural light is very variable during the day and year. For this reason the daylight is described by the relative values which are not affected by the changes and the evaluation of the daylight, the daylight factor D (\%) is used. It is the ratio of the illuminance in a given control point in the interior to the illuminance in a control point on a horizontal unobstructed plane under the specific sky conditions. Daylight factors for given visual tasks and activities are prescribed by national standards [2].

The second aspect is the energy intensity of the lighting. Within this aspect is checked if the required photometric parameters have been achieved in an energy efficient manner. The energy intensity of the lighting is evaluated by overall specific electricity consumption for the lighting per year LENI (kWh/m $\mathrm{m}^{2}$.year). For individual application areas, such as office buildings, industrial buildings, hospitals, etc., the typical values of $L E N I$ are prescribed in the standard [3].

\section{Compatibility of hygienic and energetic aspects}

The overall view on the interior lighting in buildings and its energy intensity shows that relationships among the above mention parameters exist, but these relationships are not clear. There is no simple links between the contribution of daylight and general lighting requirements, nor link between light and its energy consumption. Furthermore, in the design of interior lighting the each parameter is applied in a different manner.

In the case of general lighting requirements, the main parameter $E_{\mathrm{m}}$ illuminance $(\mathrm{Ix})$ is prescribed for all interior spaces of the building, which are used by people. Meeting the requirement for the daylighting $D(\%)$ is not required in the whole building, but only in spaces where the people spend a significant part of the day, such as offices, homes, workshops etc. Energy intensity of the lighting expressed by parameter LENI $\left(\mathrm{kWh} / \mathrm{m}^{2}\right.$.year) is evaluated for the building as a whole. Unclear relationships among parameters and a different manner of the application in the practice cause incompatibility of these aspects. 


\section{Lighting design optimization}

Optimization of the lighting means a design of such lighting system that ensures compliance with all hygiene lighting requirements at minimum cost and energy consumption. How to optimize the lighting system, when the incompatible parameters in the design process are used? The first step is to find a quantity that is able to express the hygienic and energetic aspect at the same time. Such a quantity is the luminous flux $\Phi(\mathrm{Im})$, which is the radiant flux evaluated by the human eye of the standard photometric observer. Ability to express both those aspects not so much to do with the definition of this quantity, but rather with the fact that the luminous flux is the parameter of light sources that supply the luminous flux, and this supply is associated with a certain energy consumption.

Another question is, in which stage of the project to begin the lighting optimization. Energy intensity of the lighting is connected with the design of the building structure in initial phase of the project, when also the daylight system is created. For comprehensive lighting optimization is necessary to start with lighting design in the initial phase of the building project and to integrate it into the overall solution of energy performance of the building. Efficiency of the lighting optimization in a building with existing daylighting system is greatly reduced. For this reason, it is appropriate to propose a method of the lighting optimization, which will be possible to use in the early stages of the project. It is important that the newly proposed method was simple and understandable, and was allow easy communication between different professions that deal with optimizing energy performance of the entire building.

\section{Lumen concept method}

The newly proposed method named Lumen concept differs from the traditional process of lighting design and understands light as one of the media (water, heat, air, etc.) necessary for the operation of the building. The method is based on the fact that in the initial phase of the project are known the following information:

- purpose of a building (lighting parameters, schedule of the usage);

- space requirements (rooms area);

- location of the building (geographic location, orientation, surrounding);

- land area and height regulation.

Purpose of the building specifies general lighting requirements $\left(E_{\mathrm{m}}\right)$ and the contribution of daylight $(D)$ in typical spaces of the building (offices, communications, technical rooms etc.) And at the same time the purpose of the building defines the time of spaces usage during the day and year. The time usage is different for office buildings, schools, hospitals etc. Space requirements determine the area of typical spaces. Location of the building, which is associated with geographic coordinates, orientation and screening obstacles (terrain and surrounding buildings), determine the course of daylight in the place. Land area and height regulation in the context of the screening obstacles determines the maximum area building envelope and thus the maximum amount of daylight, which is able to utilize.

The above mentioned input data allows determining the luminous flux $\Phi(\mathrm{Im})$ and quantity of light $Q_{\mathrm{v}}$ (Im.h/year), which is necessary to deliver into the building during the year, to ensure hygienic requirements. The final quantity of light will be partially delivered by daylight system and partially by artificial lighting system. The ratio of the two parts of the quantity of light delivery should be optimized in terms of energy consumption; however, the minimum contribution of daylight is given by hygienic requirements. The overall energy intensity of the lighting is determined by the sum of the energy consumption of both lighting systems.

Simplified procedure for application of the new method is as follows. Based on the purpose of the building, general lighting requirements by means of illuminace levels $E_{\mathrm{m}}$ for all typical spaces are determined. Based on illuminace level and areas of typical spaces the ideal luminous flux $\left(\Phi_{\mathrm{i}}\right)$ is calculated. In situation without daylight is necessary to ensure that the luminous flux by artificial lighting system. Based on the space utilization (geometry and reflectance), the efficiency of the lighting systems and luminaires, the real luminous flux $\left(\Phi_{\mathrm{r}}\right)$ is evaluated. Selecting lamps and control gears is then determined the real power of the artificial lighting system $\left(P_{\mathrm{r}}\right)$. With the aid of usage schedule of typical spaces is calculated the total quantity of light $Q_{\mathrm{v}}$ (Im.h/year), which is necessary to supply into the building during the year.

The schedule of the usage of typical spaces determines the number of hours with and without the daylight. The minimum value of the quantity of light provided by daylight is given by hygienic requirements. The maximum value of the quantity of light provided by daylight depends on the design of the building, the surrounding obstacles, geographic location and orientation. The range between minimum and maximum contribution of daylight in real conditions vary for different models of sky, which are typical for the site. The daylight system can be understood as a system of technical equipment (windows, skylights, skylights, etc.), which have their energy consumption, similar to luminaires, but it varies during the hours, days and months in dependence on climatic conditions.

Based on the energy consumption of daylight and artificial lighting systems is possible to optimize the design of lighting from cost and energy point of view and also in terms of lighting control systems applied for combine usage of both systems.

\section{Important topics}

To use and verification of the proposed method in practice is necessary to solve several topics. For individual types of buildings is necessary to suggest groups of typical spaces that include the rooms with identical or very similar characteristics and activities, which have the same general lighting requirements and daylight contribution requests. Such typical spaces are internal communications (staircases, corridors, foyer etc.), offices (cellular, openplan), technical rooms (boiler room, switch room) and other.

In the current standards the illuminace values are prescribed and controlled not only on the working plane and in the place of visual task, but also on main room surfaces (walls, ceiling). This fact is necessary to take into account in the calculation of required luminous flux. The method for the calculation of the luminous flux, which ensures prescribe illuminances is necessary to propose a simple method, similar to the lumen method.

To determine the total quantity of light per year and its components (daylight, artificial light), is necessary to work up yearly schedules of usage for typical spaces (in sufficient detail e.g. hourly intervals) in different types of buildings. In these schedules is important to distinguish the time when typical spaces are used for the main activity (e.g. administration, teaching, etc.) and for secondary activities (e.g. cleaning, security, maintenance). It is also necessary to differ the time periods with and without daylight. 
Daylighting is currently evaluated by the daylight factor. This factor does not depend on changes in daylight during the day and year, or on points of the compass and therefore is unable to express the real value of the daylighting in lux. Basically, this factor evaluates the size of the window openings or skylights. In practice, it uses for verification that, by given size of the window openings are fulfilled requirements for daylighting requirements in a given area or working zone. Simply, the daylight factor sets the minimum size of the window openings and thereby determines the minimum contribution of daylighting in the building. The maximum contribution is based on the maximum poss9ble size of the window openings in the building. To determine the real maximum and minimum contribution of daylighting in lux, is necessary to provide a real distribution of daylight in the building at the minimum and maximum size of the window openings for a given geographical location, and orientation of the building and surrounding of the building for standard general skies [6].

To assess the energy performance of the lighting system it is necessary to propose a method for evaluation of the energy performance of windows, skylights and light guides. These elements of daylight systems is possible to perceive like a luminaires, with own energy consumption, which changes throughout the hours, days and months in dependence on weather conditions.

\section{Conclusion}

The proposed method is characterized by a clear link between the lighting and energy parameters. After determining of the required luminous flux and quantity of light, based on the dimensions and usage of the building, it is possible in easy way to compare the energy performance of variant solutions, different types of lighting systems, luminaires or lamps. From the total quantity of light needed for the building, based on hygienic requirements, is possible to determine the part, which has to be delivering by the daylight system. Then is possible to take a rest part of quantity of light and compare the energy intensity of delivery in case of daylight and artificial lighting systems. It is also possible to make the evaluation of the benefits of the lighting control systems usage from energetic and economic point of view.

\section{REFERENCES}

[1] ČSN EN 12464 - 1 Světlo a osvětlení - Osvětlení pracovních prostorů - Část 1: Vnitřní pracovní prostory, 2012

[2] ČSN 730580 Denní osvětlení budov, 2009

[3] ČSN EN 15193 Energetická náročnost budov - Energetické požadavky na osvětlení, 2008

[4] Škoda, J.; Baxant, P. Control of lighting systems using compact systems. In Proceedings of the $11^{\text {th }}$ International Scientific Conference Electrical Power Engineering 2010. Brno University of Technology. 2010, p.797-798. ISBN 978-80-2144094-4.

[5] Škoda, J.; Baxant, The reduction in electrical consumption through proper lighting. In EPE-Electric Power Engineering 2009. p.1-5. ISBN 978-80-248-1947-1.

[6] CIE ISO 15469:2004(E)/CIE S 011/E:2003: Joint ISO/CIE Standard: Spatial Distribution of Daylight - CIE Standard General Sky, 2003.

\section{Authors:}

ing. Petr Žák, Ph.D.

Czech Technical University in Prague, Faculty of Electrical Engineering, Technická 2, 16629 Prague 6, Czech Republic, e-mail: zakpetr@fel.cvut.cz

prof. Ing. Jiři Habel, Dr.Sc,

Czech Technical University in Prague, Faculty of Electrical Engineering, Technická 2, 16629 Prague 6, Czech Republic, e-mail: habel@.fel.cvut.cz

Ing. Zuzana Panská,

Czech Technical University in Prague, Faculty of Electrical Engineering, Technická 2, 16629 Prague 6, Czech Republic, e-mail: pelanzuz@fel.cvut.cz 